\title{
Female "Circumcision"
}

\section{African Women Confront American Medicine}

Carol R. Horowitz, MD, MPH, J. Carey Jackson, MD, MPH

$\mathbf{T}$ he practice of female "circumcision," or traditional female genital surgery, is simultaneously complex and controversial. Although some consider it a human rights infringement, others view it as an integral part of cultures in which it remained unchallenged for centuries. With more than 30,000 Africans entering the United States in the last decade, American clinicians are challenged with meeting African women's health needs, as they are barraged with a debate about the ethics and politics of circumcision.

There are significant medical sequelae and public health ramifications of female circumcision; therefore most U.S. physicians probably would agree that programs to abolish it should continue. However, although there is ample media and political attention to this volatile issue, there is a relative dearth of practical, clinical information available to providers who care for circumcised women and their families. As African communities and advocates grapple with how to stop this practice, circumcised women need clinicians familiar with these surgeries, who will move beyond negative feelings they may have about the practice in order to treat women knowledgeably and with dignity. It is important to distinguish respect from unreflective acceptance. However, blanket condemnation by health workers will not help families decide how to break a long-standing tradition by choosing not to circumcise their daughters. On the contrary, by unwittingly conveying revulsion toward circumcised women and children, providers may drive these families away from the health care they need.

Our objective is to understand and address the conflicts that occur when clinicians provide care to patients whose

Received from the Departments of Health Policy and Medicine of the Mount Sinai Medical Center, New York, NY, and the Department of Medicine of the University of Washington, Seattle.

Presented as an oral abstract at the national meeting of the Society of General Internal Medicine, May 4-6, 1995.

Dr. Jackson was supported in part by the Opening Doors Project funded by the Robert Wood Johnson Foundation and the Henry Kaiser Family Foundation. Dr. Horowitz was a fellow in the Robert Wood Johnson Clinical Scholars Program.

Address correspondence and reprint requests to Dr. Horowitz: Department of Health Policy, Mount Sinai Medical Center, Box 1077, One Gustave L. Levy Place, New York, NY 10029. beliefs and practices differ from their own. We review the practice, cultural significance and medical complications of female circumcision, and offer sensitive clinical guidelines, illustrated by case examples, for caring for currently circumcised women.

\section{METHODS}

To explore the issue of ritual genital surgery, we conducted an extensive literature review and compared our clinical and community outreach experience with that of other experienced clinicians in the United States and Canada. We supplemented this information by soliciting the perspectives of East Africans from Ethiopia, Eritrea, and Somalia. Ninety-three percent of African refugees are from these areas; over $80 \%$ of women from these countries are circumcised. ${ }^{1}$ We conducted informal discussions and clinical interviews with 40 Somali, 3 Eritrean, and 2 Ethiopian women, and 5 Somali men. All the Somali women, aged 18 to 68 years, were infibulated. The Ethiopian and Eritrean women, aged 30 to 52 years, had circumcisions ranging from removal of the clitoral foreskin to infibulation. The men ranged in age from 18 to 75 .

The men and women were interviewed when they came for routine medical visits to a refugee clinic, or when the interviewer visited them in their homes. Although the study was exempt from federal regulations for the protection of human subjects, verbal informed consent was obtained, and persons who wanted to review and comment on papers that included their ideas were given the opportunity to do so. Trained medical interpreters assisted all nonEnglish-speaking patients. Gender-matched interpretation was provided, and interpretation was phrase-by-phrase with time allowed for cultural annotation. Using notes and quotations from these discussions, and information from the literature and pooled clinical experiences, we developed guidelines for caring for circumcised women.

We elicited feedback on the clinical guidelines from U.S. and Canadian clinicians and experts on the practice. To explore the representativeness of our findings and the cultural appropriateness of our guidelines, we also reviewed our findings with 20 East African women (including 5 of the Somali women initially interviewed) living in the United States, with varying degrees of acculturation. Although they agreed with the majority of points, they had passionate and polar ideas about whether clinicians 
should support circumcised women without judgment, or use their social authority to put an end to this practice. The powerful, visceral responses this topic provokes underscore how difficult this area is for clinicians to negotiate.

\section{TYPES AND TERMINOLOGY}

Many African women label this practice "genital mutilation," believing "circumcision" to be deceptive. Other women do not consider their bodies mutilated and find the former term judgmental and inflammatory. We use the term "circumcision." More neutral and more accurate terms now coming into use are traditional, or ritual female genital surgery. There are many forms of circumcision, broadly grouped as excision and infibulation, distinguished by whether labial edges are fused after the genitalia are incised (Figs. 1 and 2). Excision entails cutting or removing part or all of the clitoris, with or without the labia minora and majora. Some women have only the clitoral prepuce removed. Infibulation (radical circumcision) is excision accompanied by suturing closed the introitus, leaving a small opening for passage of urine and menstrual blood. Local customs dictate the timing and form of circumcision chosen. Females are usually circumcised between birth and 8 years of age, although occasionally up until the birth of their first child. In two studies, women preferred more severe forms of circumcision than did men, ${ }^{2,3}$ and in one study, educated and urbanized females tended to have less severe forms. ${ }^{3}$

\section{HISTORY, EPIDEMIOLOGY, AND LEGALITY}

There are signs of clitoral excision from the sixteenth century BCE. ${ }^{4}$ Although many consider it an Islamic tradition, circumcision predates Islam, is practiced by several religious groups, and is not performed in most Moslem countries. There are more than 110 million circumcised fe- males worldwide. It is most prevalent on the African continent's equatorial band (Fig. 3). Its prevalence varies from over $90 \%$ in Somalia to less than $10 \%$ in Arabic nations. ${ }^{5}$ Overall, $15 \%$ of these surgeries worldwide include infibulations. ${ }^{6}$ Infibulation is mainly practiced in the horn of Africa; over $80 \%$ of circumcised women in Sudan and Somalia are infibulated. ${ }^{7,8}$ The prevalence of mild forms, such as removal or cutting of the clitoral prepuce (analogous to male circumcision) is unknown, although it has been described in the literature. ${ }^{9,10}$

The practice of female circumcision is not unknown in the West. Clitoridectomy was performed into the 1940 s to treat masturbation, insanity, epilepsy, and hysteria. ${ }^{11}$ In the United States, physicians have also incised the clitoral prepuce to treat frigidity, ${ }^{12}$ and perform aesthetic vaginal labioplasties to reduce the size of the clitoris and labia. ${ }^{13}$ African immigrant girls have undergone genital surgeries in Europe and Canada, and London physicians performed clitoridectomies on refugees in the $1980 \mathrm{~s}^{5}$ There are anecdotal reports of such genital surgeries in the United States, and of refugee girls having ritual circumcisions during visits to their native countries.

Female circumcision is illegal in several African and European countries and in Canada. As of September 1997, it will be illegal in the United States to circumcise females under the age of 18 (Prohibition of Female Genital Mutilation Act of 1995. H.R. 941, Feb. 14, 1995). The U.S. Congress also mandated the Department of Health and Human Services to educate communities on the health effects of the practice and make recommendations to medical schools for its treatment. The U.S. Immigration and Naturalization Service granted political asylum to a Togolese woman, recognizing that her likelihood of being circumcised constituted a bona-fide fear of persecution (Dugger C. New York Times. 1996;145:A1, B6-7). There are now public health campaigns in many countries that educate communities about the harms of circumcision with the goal of eradicating the practice. ${ }^{14}$

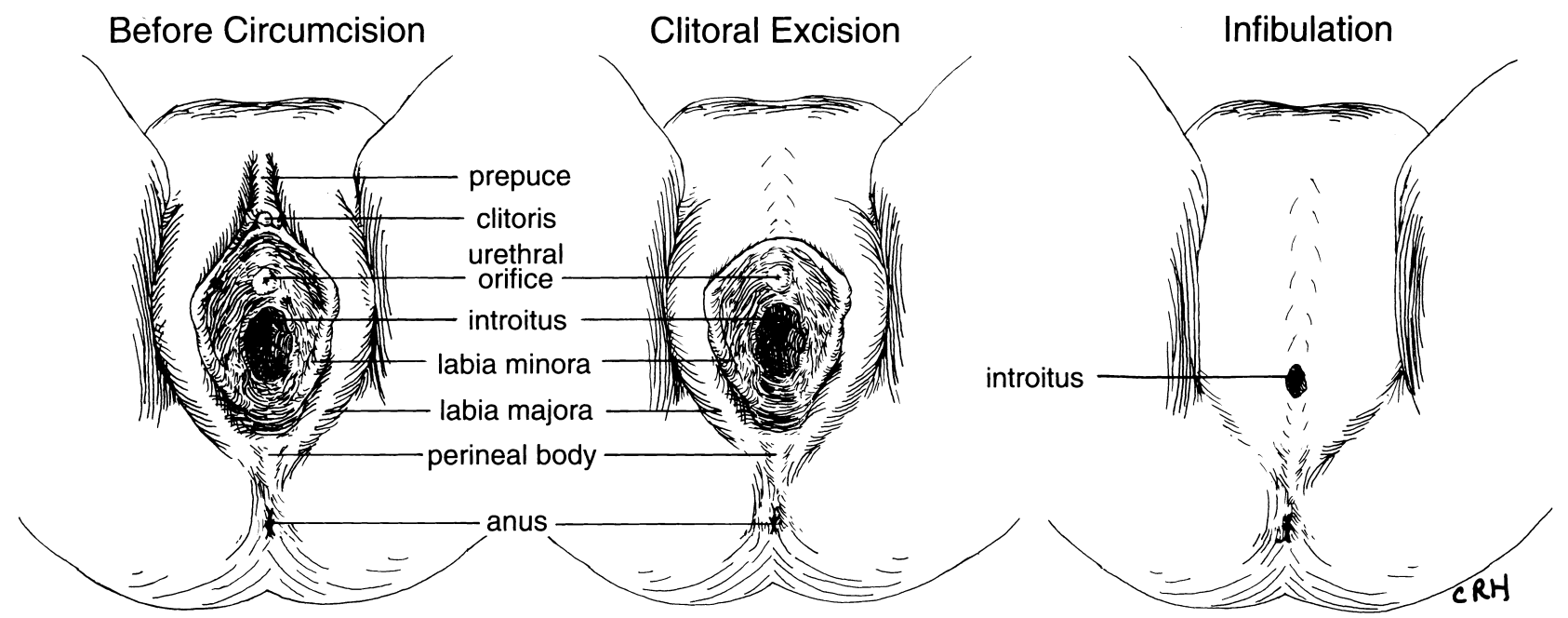

FIGURE 1. Types of female circumcision. 


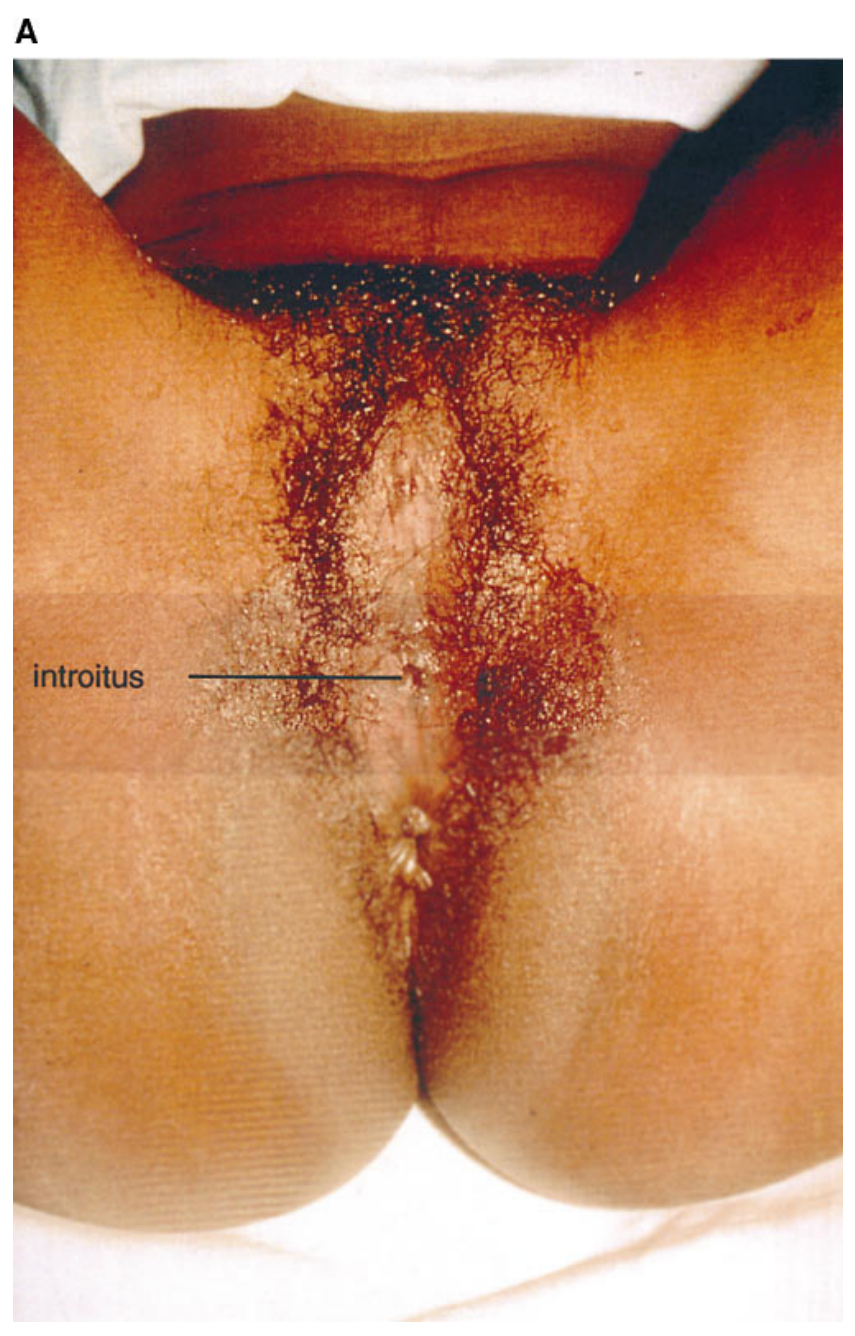

B

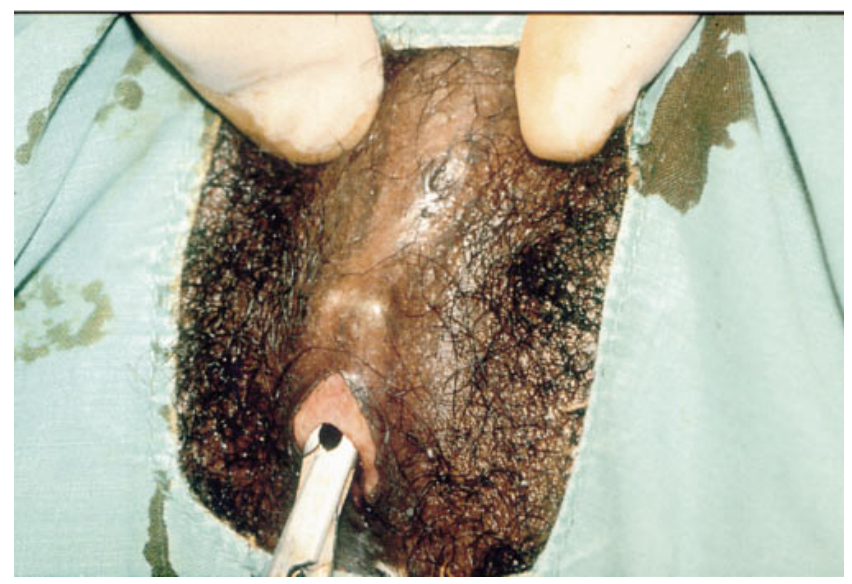

FIGURE 2. A 28-year-old Somali woman requesting defibulation prior to marriage: $(A)$ perineal region; $(B)$ close-up of the introitus.

\section{THE PRACTICE}

Although health workers may circumcise females using aseptic technique, medically untrained persons usually perform circumcisions without anesthesia in nonmedical settings. Circumcisers may be skilled in traditional medi- cine, but their lack of training in surgery, their poor equipment, and the fact that the girl may struggle, all suggest that it is difficult to be precise in an excision. For infibulation, the wound edges are closed with thorns or sutures, and the thighs may be bound together to fuse the labial edges, with a matchstick or twig inserted to ensure a patent vaginal foramen. ${ }^{7}$ Some women vividly recall their circumcision as a traumatic and painful experience. A 62-year-old Somali woman recalled, "It was the most painful experience of my life. My father did not want it done; he begged my mother to stop. Six women held me down on the ground. Another woman cut me with a blade. She closed me with thorns. I thought I'd die from the pain." Other women have no memory of the procedure or recall only a celebration.

Defibulation, cutting or tearing open of the scarred vaginal tissue, occurs partly when an infibulated woman has intercourse, and more extensively when she gives birth. In many cultures, a husband defibulates his bride after seeing she is a virgin. A woman may be defibulated with a sharp instrument if the husband is unable to penetrate, or if he permits defibulation by a midwife or relative. ${ }^{7}$ Women can be surgically defibulated electively, or for medical reasons. Reinfibulation, most commonly practiced in the Sudan, involves resuturing of the introitus after childbirth or widowhood. Some sexually active, unmarried women use reinfibulation to create a false appearance of virginity. ${ }^{15}$

\section{CULTURAL SIGNIFICANCE}

Clinicians who work with culturally diverse patients often encounter patients who adhere to practices the clinicians do not understand. As members of noncircumcising cultures, our first response is to wonder why it is performed and perpetuated, and what values it signifies and sustains. We must curb a tendency to view behavior as rational or irrational from a rarified clinical perspective. Rather, we can see behaviors within the context of patients' lives and relationships. Although there is no single cultural explanation for female circumcision, there are several general points to make when attempting to place it in an understandable context.

First, until recently in the societies in which it is practiced, circumcision has been regarded as a necessary condition of life. The concept of female (and male) circumcision, as with many traditions, can be invisible until people are forced to examine it. This may explain why nearly half of the Nigerians in one study gave as their reason for the practice, "It is the custom of our people." ${ }^{16}$ A 36-year-old Ethiopian woman explained, "I had the foreskin on my clitoris removed as a baby, just like my brother . . . Why does everyone say it is so terrible and that I should have problems from it?" Circumcised female genitalia are considered normal to some Africans, just as circumcised male genitalia are normal to many Americans. As a 30-year-old infibulated Somali woman explained, "I want doctors to know that the way I look is normal for me." A woman may desire circumcision to be marriageable, or chaste, for aesthetics, or to conform to 


\section{FEMALE CIRCUMCISION}

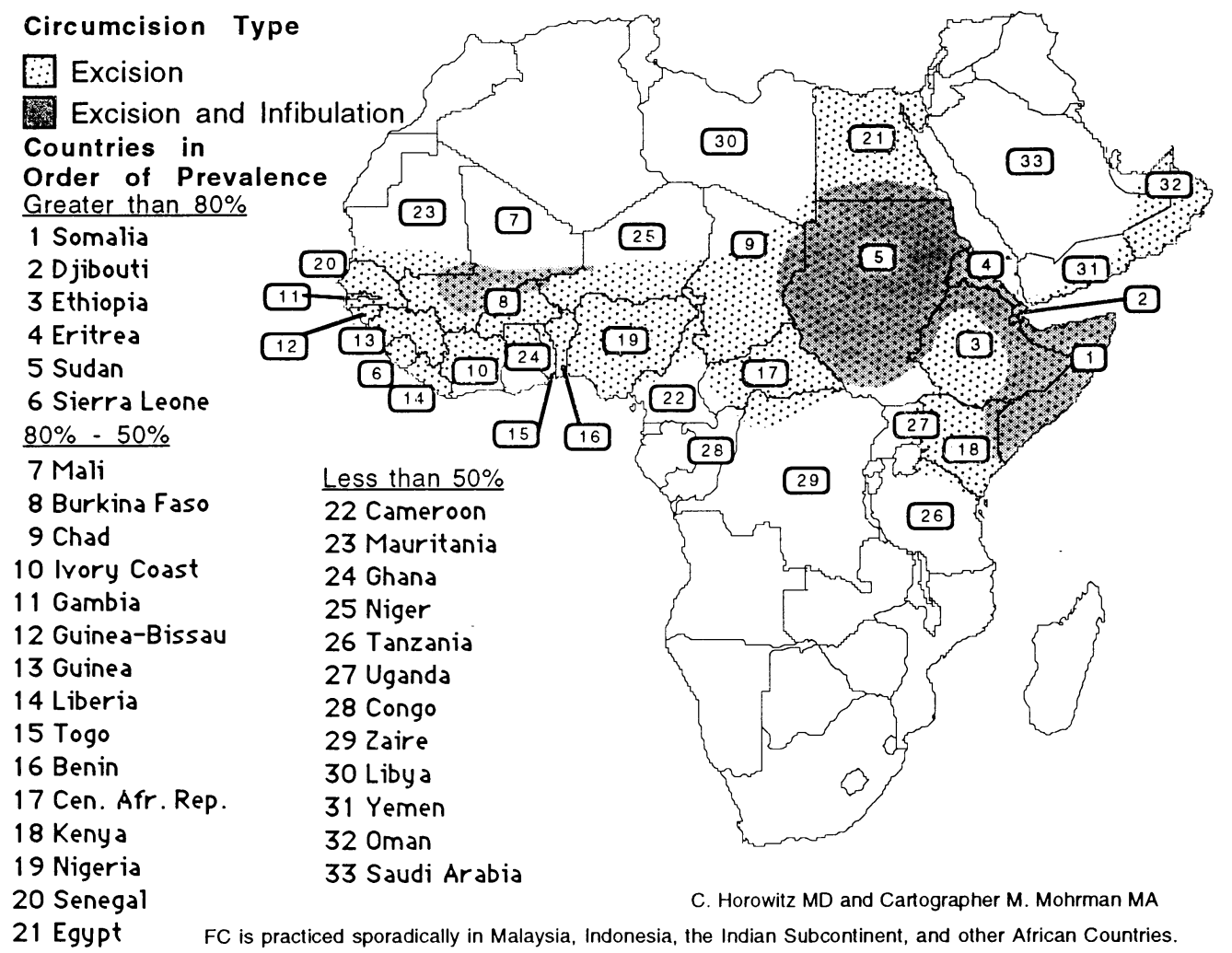

FIGURE 3. Estimated prevalence of female circumcision in Africa, by country. ${ }^{4,5}$

tradition. Reasons for deeply rooted traditions are often difficult to articulate, and therefore are easily discounted.

Second, although many treat ritual female genital surgery as a singular process affecting millions of women, it is not a homogeneous practice. The types of surgeries and rationales behind them are as diverse as the people that practice them. As with all traditional beliefs and practices of culturally diverse patients, it is important not to overgeneralize information learned from one group, but to learn from each patient community the significance of a practice (such as circumcision) for them.

Third, although efforts to elevate the role of women in African society will most likely include a discussion of ritual genital surgery, women may not consider it the central issue of inequality. Africans must debate the timing and framing of social change in Africa within the context of their families and neighborhoods. ${ }^{17}$ The modification or elimination of ritual genital surgery depends on opposition by families and religious and community leaders, not outsiders, however well intentioned. ${ }^{14}$

Finally, although these practices probably have their origins in patriarchal authority, women are responsible for their day-to-day perpetuation. A woman who rebels against a community in which circumcision is uniformly practiced by not circumcising her daughters may endanger her family's social and economic support system, making circumcision the safer of her suboptimal choices. "Hence the paradox - the victims of the practice are also its strongest proponents", according to a World Health Organization report. ${ }^{18}$ Men and women together create social expectations and resist change. A 45-year-old Eritrean man said, "My wife wanted to do this, and I did not object. Where we come from, it is the natural practice of our people." We must frame efforts to deter circumcision within the larger family and community that will be affected by, and respond to, a woman's decisions.

\section{MEDICAL SEQUELAE AND THEIR MANAGEMENT}

More than half of circumcised women may experience medical complications, but there are few accurate assessments of the frequency and severity of complications. The literature focuses on the sequelae of severe forms (especially infibulation), and we shall concentrate on this information. There are no assessments of the complications of less severe forms, such as excision of the clitoral foreskin.

Western providers will most likely encounter delayed complications of infibulation, ${ }^{19}$ whose severity usually correlates with the extent of introital obstruction or scarring. Infibulated women can have keloids, adhesions, and dermoid cysts that obstruct the introitus, or further narrow the vaginal opening. An obstructive vulval skin diaphragm leads to a poor, slow urinary stream, dribbling, incontinence, and vaginal calculi, ${ }^{20}$ and maintains a blind 
pouch around the urethra and vagina, resulting in frequent vaginal and urinary tract infections. ${ }^{21}$ A narrow introitus may also obstruct passage of menstrual blood and result in dysmenorrhea and hematocolpos (painful retention and accumulation of blood in the vagina).

A narrow introitus may prohibit a pelvic examination or obtaining a clean-catch urine sample. In this case, clinicians can diagnose urinary tract infections by the presence of symptoms, bacteriuria, and white blood cell counts (bacteriuria alone may be present without infection owing to the mixture of urine and vaginal secretions in a narrow introitus). Vaginal candidiasis can be diagnosed using a cotton swab specimen, and patient symptoms can be treated with oral, rather than vaginal antifungal agents.

If a woman has recurrent infections, or significant obstruction of urine or menstrual blood, clinicians can refer her to a gynecologist for defibulation or stretching of vaginal tissue. Women with obstructive sequelae may not agree to these procedures prior to first intercourse or marriage. Although such a choice may be frustrating for their clinicians, patients have the right to make this decision, and clinicians can be invaluable to these patients if they manage these problems medically, and gently present these options again on future occasions.

Another set of complications may manifest when women become sexually active. If an infibulated woman's narrow introitus tears "naturally" (by penile penetration) or is cut for first intercourse, local infections and laceration of adjacent tissues may occur. This may lead to uterine and rectal prolapse, and vulval lymphedema. ${ }^{22}$ Physicians can perform defibulation under local or general anesthesia in an ambulatory setting. ${ }^{23,24}$ Women who are reinfibulated after birth may again suffer obstructive sequelae. Circumcised women have an increased risk of infertility, in part due to chronic pelvic infections and obstruction to intercourse. ${ }^{25}$

There are no carefully controlled studies of the effect of female circumcision on sexual functioning. Most clinicians, however, assume a woman will have diminished sexual sensation if her clitoris is removed. Clinicians should note that some circumcised women report having satisfying sexual relations: one study of 300 infibulated Sudanese women found that the majority reported experiencing sexual desire, pleasure, and orgasm, despite a cultural norm to hide these experiences. ${ }^{26}$ Fear of first intercourse is common among infibulated women. Women may fear the pain of defibulation, or the possible discovery by their husbands that there was an accidental disruption of the circumcision, which could result in social humiliation and familial disgrace. Dyspareunia may occur from difficult penetration, scarring, and mental trauma. Anxiety and phobic behavior may occur, as some women psychologically re-experience the pain and trauma of the procedure and its complications. ${ }^{4}$ However, the psychological sequelae are not well elucidated and deserve further attention.
Obstetric complications are common. If scar tissue exists, women must have an anterior episiotomy before delivery, for the inelastic tissue cannot dilate and may cause urethral obstruction, perineal lacerations, and postpartum hemorrhage, and prevent the infant's descent. Prolonged pressure on the perineum during delivery can lead to avascular necrosis and atrophy of genital tissue, rectovaginal and vesiculovaginal fistulae. ${ }^{19}$

\section{EXPERIENCE OF CLINICIANS}

When American clinicians are first exposed to circumcision, they may respond with shock, disbelief, psychological and even physical distress. In one study, more than $50 \%$ of health workers felt horror and revulsion, and over 30\% were nauseated on first hearing about infibulation. ${ }^{27}$ Providers are often unfamiliar with ritual practices and ways to approach the issue with their patients. Uncertainty and discomfort may cause a provider to avoid the issue and their patient.

Clinicians who disagree with their patients' choices face a conflict of three sets of values: those of their profession (with a tendency to medicalize, or focus on the medical aspects of a practice such as circumcision, isolating it from the complex cultural practice of which it is but one part); their personal (moral, political and social) values; and the unfamiliar values of their patients. Clinicians can learn to separate their feelings about the practice from their obligation to care in a nurturing way for circumcised women. Otherwise, judgmental attitudes may offend patients (who probably had no say in the decision to alter their genitalia), inhibit further medical care, and impair the trust and rapport necessary to discuss health issues and the potential harms of continuing the practice.

\section{CULTURAL CONFLICTS AND MISCOMMUNICATIONS}

African immigrants and refugees in the United States experience a marked discrepancy between their traditional culture and their new culture. In general, they have a strong reliance on and value community affiliation over individualism. In Africa, a male family member's permission is often necessary for decisions about reproductive health issues. The American medical system positively values patient autonomy, at times excluding family members during private discussions. Community members or leaders may advise African immigrants about where and from whom to seek care, as well as the type of problems appropriate to bring to a medical encounter. News of a troublesome encounter with a specific provider or clinic may quickly spread through an entire community.

In these small communities, interpreters have significant social influence. For this reason, patients worry information will be circulated outside the encounter. As a Somali adolescent said, "I am so glad I can speak English. I don't talk to other girls about this-and the interpreters, they will gossip." Even a well-trained interpreter repre- 
sents a third person in the medical encounter and diminishes the mental safety of a private and intimate providerpatient interaction. Certainly, family members who may disagree with, or be embarrassed by, a woman's concerns or questions are inappropriate sources of interpretation.

Immigrant women often see male providers who are unfamiliar with their culture, and their voices are heard through interpreters. Infibulated women have been offended by physicians who, on first seeing their genitalia, asked if they had been in an accident, or splashed with acid. They may not agree with some clinicians' assumptions that all circumcised girls and women have complications, or need medical care for circumcision. In our experience, many women, whether excised or infibulated, have no complaints related to their altered genitalia, and do not prefer that special attention be devoted to this issue. These women may not understand why we medicalize circumcision, which they consider a tradition, not a medical procedure. A 50-year-old mother of six stated, "This was not done by a doctor, and I was never sick from it. If you're not going to help me circumcise my daughter, why are you asking all these questions?" Women's discomfort with physicians' focus on this remote event is echoed by a 65-year-old woman, "Why do you ask me so much about this? . . My back hurts, I need a job, and my family to be together again. These are my problems."

Although many African women are quite sophisticated, rural and poor women may have little reproductive health education, or experience with gynecologic examinations. A woman may have difficulty answering medical questions if she is unfamiliar with noncircumcised anatomy, or with what she had removed by circumcision. She may fear examinations if she believes a clinician will react negatively to her circumcision. Patients never before exposed to procedures such as pelvic examinations could understandably find these alien as well. Women are also offended by Western clinicians' tendency to show physical findings to their colleagues. A 34-year-old infibulated Somali woman explained, "Doctors should know we are modest. We don't want to be touched just so they can see how we are different, and we don't want to be shown to other doctors."

Many refugees who arrive in the United States have spent years in refugee camps, and faced war, starvation, rape, torture, and loss of family, homes, and their way of life. Their priorities are obtaining homes, jobs, and food, supporting their family members still abroad, and recovering from the traumas of war and relocation. Many expatriates plan to return to their country of origin, and they base decisions for themselves and their families on how these choices will be viewed "back home." For many women, circumcision is a source of pride and belonging, and it is widely accepted and expected. In two studies of women in Somalia, for example, all stated they would circumcise their daughters, and most preferred infibulation. ${ }^{8,28}$ When exposed to Western culture, they face a transition from taking circumcision for granted to living where it is considered "torture” (Rosenthal A. New York Times. 1992;142:A15), an "atrocity," "barbarism" (French M. Washington Post. 1992; 115:F1), "unconscionable child abuse," "a brutal, savage practice” (Raspberry W. Washington Post. 1993;116:A21), and is usually called "mutilation." Because of these tensions, obtaining medical care can be a harrowing and alienating experience for circumcised women.

\section{CASE EXAMPLES}

We offer examples of two common reasons circumcised women seek care, and ways clinicians can work with them, followed by general clinical guidelines:

\section{Case 1: Defibulation Prior to Intercourse}

An 18-year-old infibulated Somali woman came to a refugee clinic to have health forms filled out for English as a second language classes. During the interview, she stated she was not sexually active. An untrained interpreter who was present told the physician not to ask about sex, as women of her culture never discussed it. The clinician explained to the interpreter that the topic was also uncomfortable for many American-born women, and they discussed a sensitive way to proceed.

They explained to the patient that if she ever did become sexually active, she would need to take precautions about pregnancy and sexually transmitted diseases. The patient was also informed that if she chose to have intercourse, she would not be judged harshly and that if we "opened her" prior to first intercourse, it would be less traumatic.

Two weeks later, the woman arrived in clinic with a man she introduced as her boyfriend. She stated that they had decided to marry, but knew that her friends who had been married had been opened by their new husbands and that this caused a lot of pain, bleeding, and other problems. She asked that the clinician open (defibulate) her and was referred to the gynecology department, where this was performed uneventfully.

Case Notes: The clinician educated this woman in a nonthreatening way so she felt comfortable returning for further consultation. The interpreter taught us how to use culturally appropriate language, and the meanings of various Somali terms. ${ }^{29}$

\section{Case 2: Vaginal Infection in an Infibulated Woman}

A 21-year-old Somali woman was seen with an interpreter. She noted pain in her abdomen, especially when she was menstruating. She was fully veiled, and when she spoke of this, she covered her face with her coat and giggled. The provider said, "I know that some women in your culture have been closed. Sometimes that causes problems for them, including pain during menstruation. Were you closed?" 
Provide female clinicians and interpreters when possible.

Work closely with professional medical interpreters; avoid using family members as interpreters.

Have a brief previsit consultation with an interpreter to summarize issues expected for the encounter, become informed about traditional practices, and elicit suggestions for how to proceed, especially with sensitive issues.

Encourage interpreters to discuss potentially offensive questions with you before interpreting them to the patient.

Make confidentiality explicit.

Develop collaborations between communities and your institution (i.e., invite community groups to educate staff about their culture and encourage students and residents to learn from community groups).

Understand medical and social aspects of traditional surgery, and become comfortable with your own opinions and emotions before seeing patients.

The patient said she had been infibulated by an elder woman in her village as an 8-year-old and now had a slow urinary stream (taking 5-10 minutes to pass urine), felt that her menstrual blood got stuck, and recently noted a whitish discharge. Two weeks before this visit, she had been seen by another physician who gave her antifungal vaginal suppositories. Although she tried to insert the medication into her narrow introitus (borrowing an insulin syringe from a friend for this purpose), she was unable to insert much medicine, and the cream would get stuck and thicken in her introitus.

On physical examination, she had been infibulated (though her clitoris was palpable beneath the skin) and her introitus was only $5 \mathrm{~mm}$ wide. Cotton swab examination of the introitus revealed multiple budding yeast with hyphae. She was treated with an oral antifungal agent for the vaginal infection and given a nonsteroidal anti-inflammatory agent for menstrual pain, with complete resolution of her discomfort. A vaginal ultrasound during her menses revealed no hematocolpos.

The patient was advised that she could have either defibulation or stretching of her introitus, but she refused the procedures. She was told to return if she had symptoms of urinary or vaginal infections. This physician followed the patient for the next 2 years, during which she had no further infections, and no further menstrual pain.
Case Notes: It is important to develop treatment plans based on a woman's unique clinical situation. This woman felt uncomfortable telling her first physician that she could not use a vaginal suppository, and was afraid that no other physician would treat her unless she agreed to be defibulated. Although providers may wish that a patient with obstructive complications would agree to defibulation, they cannot make this decision for the patient. Providers can, however, treat patients to the best of their ability, regardless of patients' decisions.

\section{GUIDELINES FOR CLINICIANS:}

Health centers can create or eliminate barriers for minority communities by choosing to address the issues their patients consider most important. We offer recommendations for working with African communities in Table 1, clinical pearls for treating circumcised women in Table 2, and sample questions in Table 3.

Once clinicians establish trust and dialogue with communities, they may receive requests to perform genital surgeries on children. Clinicians have a duty to inform families who want to circumcise their daughters, or who are from an area with a high prevalence of circumcision, about the complications of these practices. The physician

\section{Table 2. Clinical Pearls for Treating Circumcised Women}

Address patient-centered expectations for the medical encounter (do not prioritize circumcision above patients' own needs and concerns).

Ask about circumcision as part of a reproductive history after establishing rapport with the patient, and explain the necessity of questions about it.

Women who have complications often do not attribute them to the procedure. Therefore, ask women specifically if they have urinary, menstrual, or gynecologic difficulties, rather than if they have problems due to circumcision (Table 3).

Ask general, nonthreatening questions about circumcision so women who choose to may discuss related concerns.

Assess the patient's knowledge of her reproductive system and inform her about anatomy and function before performing an examination.

Respect the woman's modesty during the examination.

As circumcision does not guarantee "chastity," teach women about contraception.

Inform women they can be defibulated electively for problems, or prior to intercourse or delivery.

Women with obstructive scar tissue may want to be defibulated prior to first intercourse to avoid traumatic tears on penetration. Pregnant women who have obstructive scar tissue should be defibulated before their second stage of labor. 


\section{Table 3. Sample Questions to Ask Circumcised Women}

Many women from your country have been circumcised or "closed" as children. I ask my patients about this because some women have some questions about this part of their body, and others may have problems from the circumcision. If you do not mind telling me, were you circumcised or closed?*

Do you have any problems passing your urine; does it take you a long time to urinate? (Note that women with obstruction may take several minutes to pass urine.)

Do you have any pain with menstruation? Does your menstrual blood get stuck?

Do you have any itching or burning or discharge from your pelvic area?

(If sexually active) Do you have any pain or difficulty when having relations?

*If working with interpreters, practice this first question with them and elicit feedback on an appropriate way to broach the subject and a culturally appropriate name for circumcision or infibulation.

can explain that to perform these surgeries on minors is illegal in the United States, and is currently considered, by many, to be a form of child abuse.

As with all behaviors health workers try to discourage, however, providers should support families, with sensitivity and without sensationalism, or risk a backlash of secrecy and mistrust. Some African men may state they want to stop the practice. A 19-year-old Somali man explained, "I don't need it, I don't want it . . . women do this thing to girls, not men." However, women may mistrust such modern opinions. A 33-year-old unmarried Somali woman explained, "I know men say they do not care if women are closed, but that is just what they tell you. You'll see who they marry-they would never marry a girl who is not circumcised."

The strategy of medicalizing ritual genital surgery and then trying to eradicate it as if it were a disease, without recognizing the larger sociocultural context of which it is but one part, will be unsuccessful. It will continue until societies that practice it decide the practice is damaging to the welfare of women. Only efforts to improve the social and economic status of women, and education from within communities, can alter this practice. In a collaborative effort between health workers and East Africans in Canada, for example, $72 \%$ of women reported changing their attitudes from pro- to anti-circumcision. ${ }^{30}$ A 55-year-old Somali woman explained, "I am like my mother and her mother. My children are closed. They are safe, pure. Their children, I don't know. This is a different culture, things will probably change."

In our clinical setting, once we gained the patients' and community's trust, women and men would solicit our opinion and advice about circumcising their boys and girls, and community members would occasionally inform us of persons hoping to circumcise their daughters, so we could intervene before this occurred. Organizations such as Forward USA (San Jose, Calif.), the Research, Action and Information Network for Bodily Integrity of Woman (RAINBQW, New York, NY) and Equality Now (New York, NY) ${ }^{31}$ can direct clinicians who are interested in becoming more directly involved with efforts to educate about female genital surgeries.

Refugees may adhere to traditions to remain part of the culture and country to which they hope to return.
Many women fear uncircumcised children will not be part of their cultural lineage, will have genitalia considered unclean or ugly, and will not be protected from external and internal pressures to be inappropriately sexually active, without a chastity belt of flesh. A 23-year-old Somali woman lamented about her 3-year-old daughter, "Who will protect my daughter from the men at day care, and who will protect her from herself when she is older?" Other women are eager to stop the practice. Both groups of women will need the support of community members and clinicians in initiating this cultural change.

In conclusion, clinicians face a challenge when providing care to patients with beliefs and practices that differ from their own. The current Western view of female circumcision as barbaric and primitive has undoubtedly influenced clinicians' attitudes toward circumcised women. These factors contribute to African women's feelings of being misunderstood and suboptimally treated by American health care providers. Physicians should understand the medical complications and cultural context of circumcision, and clarify their own views about the practice and the patients if they are to offer quality care to circumcised women. Partnerships between clinicians and communities will promote communication and optimal care.

The authors are deeply grateful for the ideas and input of Eritrean, Ethiopian, and Somali women and men in the United States who have chosen to remain anonymous; Richard Deyo, Thomas Koepsell, and Lula Hussein for critical review of the manuscript; and Sandy Fraser and Herbert Khosid for their input and use of photographs.

\section{REFERENCES}

1. Refugee Arrival Data. U.S. Department of Health and Human Services Office of Refugee Resettlement; 1994.

2. Lowenstein L. Attitudes and attitude differences to female genital mutilation in the Sudan: is there a change on the horizon? Soc Sci Med. 1978;12:417-21.

3. El Dareer A. Attitudes of Sudanese people to the practice of female circumcision. Int J Epidemiol. 1983;12:138-44.

4. Sami I. Female circumcision with special reference to the Sudan. Ann Trop Pediatr. 1986;6:99-115.

5. Hosken F. The Hosken Report; Genital and Sexual Mutilation of Females. Lexington, Mass: Women's Int Network News; 1994. 
6. Toubia N. Female circumcision as a public health issue. N Eng J Med. 1994;331:712-6.

7. El Dareer A. Epidemiology of female circumcision in the Sudan. Trop Doctor. 1983;13:41-5.

8. Dirie M, Lindmark G. Female circumcision in Somalia and women's motives. Acta Obstet Gynecol Scand. 1991;70:581-5.

9. Asali A, Khamaysi N, Aburabia Y, et al. Ritual female genital surgery among Bedouin in Israel. Arch Sex Behav. 1995;24:571-5.

10. Grisaru N, Lezer S, Belmaker RH. Ritual female genital surgery among Ethiopian Jews. Arch Sex Behav. 1997;26:211-5.

11. Sheehan E. Victorian clitoridectomy. Med Anthropol News. 1982; 12:9-15.

12. Wollman L. Female circumcision. J Am Soc Psychosomat Dent Med. 1973;20:130-1.

13. Hodgkinson D, Hiat G. Aesthetic vaginal labioplasty. Plast Reconstr Surg. 1983;74:414-6.

14. Gruenbaum E. The Islamic movement, development, and health education: recent changes in the health of rural women in central Sudan. Soc Sci Med. 1991;33:637-45.

15. El Dareer A. Woman, Why Do You Weep? Circumcision and Its Consequences. London, UK: Zed Press; 1982.

16. Myers R, Omorodion F, Isenalumhe A, Akenzua G. Circumcision: its nature and practice among some ethnic groups in southern $\mathrm{Ni}$ geria. Soc Sci Med. 1985;21:581-8.

17. Winkel E. A Muslim perspective on female circumcision. Women Health. 1995;23:1-6.

18. World Health Organization, International Federation of Gynecology and Obstetrics. Female circumcision. Eur J Gynecol Obstet. 1992;45:153-4.

19. Verzin J. Sequelae of female circumcision. Trop Doctor. 1975;
5:163-9.

20. Aziz F. Gynecologic and obstetric complications of female circumcision. Int J Gynecol Obstet. 1980;17:560-3.

21. Agugua N, Egwato V. Female circumcision: management of urinary complications. J Trop Pediatr. 1982;28:248-52.

22. DeSilva S. Obstetric sequelae of female circumcision. Eur J Obstet Gynecol Reprod Biol. 1989;32:233-40.

23. Baker C, Wilson G, Vill M, Curet L. Female circumcision: obstetric issues. Am J Obstet Gynecol. 1993;169:1616-8.

24. Lalonde A. Clinical management of female genital mutilation must be handled with understanding, compassion. Can Med Assoc J. 1995; 152:949-50.

25. Inhorn M, Buss K. Infertility, infection and iatrogenesis in Egypt: the anthropological epidemiology of blocked tubes. Med Anthropol. 1993;15:217-44.

26. Lightfoot-Klein $H$. The sexual experience and marital adjustment of genitally circumcised and infibulated females in the Sudan. J Sex Res. 1989;26:375-92.

27. Gove S, Diamondstone L. Medical team interaction with female circumcision in a refugee camp, Bo', Somalia. Discussion Paper Series. San Francisco, Calif: Institute for Health Policy Studies, University of California.

28. Ntiri D. Circumcision and health among rural women of southern Somalia. Health Care Women Int. 1993;14:215-26.

29. Putsch R. Cross-cultural communication: the special case of interpreters in health care. JAMA. 1985;254(23);3344-8.

30. Abdi M, Adbi S. Horn of Africa Resource and Research Group. Somali Women's Community Education Project, Toronto, Ont; 1992.

31. Halim AA. Names and addresses of some organizations concerned with FC. In: Awaken. New York, NY: Equality Now; 1997:19-21.

\section{JOURNAL OF GENERAL INTERNAL MEDICINE SUBSCRIBERS Do we have your new address?}

Send us your new address three months before it becomes effective, so we will have time to get it into our computer system and ensure that your copies of JGIM continue to arrive uninterrupted. Send your old mailing label, your new address with zip code, the effective date of your new address, and your current telephone number.
Nonmember subscribers notify: Tina Lynch Blackwell Science, Inc. Commerce Place, 350 Main St. Malden, MA 02148

\section{SGIM members notify: \\ Janice L. Clements}

Society of General Internal Medicine 700 13th Street, NW, Suite 250

Washington, DC 20005 